\title{
PRÁTICA CINEMATOGRÁFICA: O CINEMA COMO POTENCIAL ÉTICO-ESTÉTICO E TRANSDISCIPLINAR NA AULA DE PORTUGUÊS COMO LÍNGUA ADICIONAL
}

\author{
PRÁCTICA CINEMATOGRÁFICA: EL CINE COMO POTENCIAL ÉTICO \\ Y ESTÉTICO Y TRANSDISCIPLINAR EN CLASE DE PORTUGUÉS COMO \\ LENGUA ADICIONAL
}

CINEMATOGRAPHIC PRACTICE: THE CINEMA AS AN ETHICALAESTHETIC AND TRANSDISCIPLINARY POTENTIAL IN THE PORTUGUESE AS AN ADDITIONAL LANGUAGE CLASSROOM

\author{
Gabriela da Silva BULLA ${ }^{1}$ \\ Ananda Vargas HILGERT ${ }^{2}$ \\ Mariana BULEGON ${ }^{3}$
}

RESUMO: Este trabalho pretende apresentar o curso Prática Cinematográfica do Programa de Português para Estrangeiros (PPE) da Universidade Federal do Rio Grande do Sul (UFRGS), discutindo algumas atividades realizadas dentro dessa proposta de ensino. O PPE é um programa de extensão que, desde 1993, tem por objetivos formar professores de Português como Língua Adicional (PLA) e oferecer aulas de PLA a alunos estrangeiros com ou sem vínculo com a UFRGS. Os cursos são elaborados a partir de diferentes temáticas e gêneros do discurso (BAKHTIN, 2003), sendo que alguns incluem a realização de projetos de aprendizagem e outros são configurados exclusivamente a partir de projetos (HERNÁNDEZ, 2008). Essas metodologias de aprendizagem, acreditamos, proporcionam mecanismos para que os alunos se insiram na e pela linguagem nas diferentes esferas de atividade humana. Consideramos o cinema não como uma ferramenta para o ensino de português, mas uma arte que tem o potencial de proporcionar uma experiência ético-estética de sensibilização diante do mundo e das mais diversas formas que nos relacionamos com as linguagens.

PALAVRAS-CHAVE: Português para estrangeiros. Português como Língua Adicional. Cinema; Ensino de línguas. Multiletramentos.

\footnotetext{
${ }^{1}$ Universidade Federal do Rio Grande do Sul (UFRGS), Porto Alegre - RS - Brasil. Professora Adjunta de Português como Língua Adicional no Departamento de Letras Clássicas e Vernáculas e Programa de Pós-Graduação em Letras. Doutora em Linguística Aplicada. ORCID: <https://orcid.org/0000-00027091-4794>. E-mail: gsbulla@gmail.com

${ }^{2}$ Universidade Federal do Rio Grande do Sul (UFRGS), Porto Alegre - RS - Brasil. Doutoranda em Educação no Programa de Pós-graduação em Educação (PPGEDU/UFRGS). Bolsista CAPES. ORCID: <https://orcid.org/0000-0003-4197-6299>. E-mail: anandavh@gmail.com.

${ }^{3}$ Universidade Federal do Rio Grande do Sul (UFRGS), Porto Alegre - RS - Brasil. Mestranda em Estudos da Linguagem, na linha de pesquisa Linguística Aplicada, no Programa de Pós-Graduação em Letras (PPG-Letras/UFRGS). Bolsista CAPES. ORCID: <http://orcid.org/0000-0002-1064-1691>. Email:bulegonm@gmail.com.
} 
RESUMEN: El trabajo pretende presentar el curso Práctica Cinematográfica del Programa de Portugués para Extranjeros (PPE) de la Universidade Federal do Rio Grande do Sul (UFRGS), y discutir algunas atividades que se han realizado dentro de esta propuesta de ensenanza. PPE es un programa de extensión que desde 1993 tiene por objetivo formar profesores de Portugués como Lengua Adicional (PLA) y ofrecer clases de PLE a alumnos extranjeros con o sin vínculo con UFRGS. Se elaboran los cursos desde distintos temas y géneros del discurso (BAKHTIN, 2003), puesto que algunos incluyen la realización de proyectos de aprendizaje y otros se configuran exclusivamente desde proyectos (HERNÁNDEZ, 2008). Creemos que estas metodologías de aprendizaje, proporcionan herramientas para que los alumnos se insieran en el y por el lenguaje en las distintas esferas de la actividad humana. Consideramos el cine no sólo como una herramienta para la enseñanza de portugués, sino un arte que tiene el potencial de proporcionar una experiencia ética y estética de sensibilización ante el mundo y las más diversas formas por las cuales nos relacionamos con los lenguajes.

PALABRAS CLAVE: Portugués para extranjeros. Portugués como lengua adicional. Cine. Enseñanza de lenguas. Multiletramentos.

ABSTRACT: This paper aims at presenting the course Cinematographic Practice offered by the Portuguese for Foreigners Program (PPE) at the Federal University of Rio Grande do Sul (UFRGS), discussing some of the activities carried out within this teaching proposal. PPE is an extension program created in 1993 with the objective of educating Portuguese as an additional language (PLA) teachers and offering PLA classes to foreigners enrolled or not as UFRGS students. The courses are elaborated from different themes and discourse genres (BAKHTIN, 2003), some of which include the development of learning projects and others are configured exclusively as projects (HERNÁNDEZ, 2008). These learning methodologies, we believe, provide mechanisms for students to engage in and through language in different spheres of human activity. We consider cinema not as a tool for teaching Portuguese, but as an art that has the potential to provide an ethical-aesthetic experience of awareness to the world and to the various ways we relate to languages.

KEYWORDS: Portuguese for foreigners. Portuguese as additional language. Cinema. Language teaching. Multiliteracy.

\section{Introdução}

Pensar em linguagem e relações humanas na pós-modernidade implica em considerar novas possibilidades de interação oportunizadas pela tecnologia. Vivemos tempos em que nos comunicamos e interagimos na e pela linguagem através de diferentes recursos, meios e configurações, o que exige reformulações na educação formal, de modo a torná-la relevante e integrada a tantas mudanças (MORÁN, 2015). Sendo assim, é necessário, em encontros educacionais, acompanhar e promover espaços 
para reflexão sobre e vivência de diferentes linguagens e modos de interação da contemporaneidade, objetivando a participação de maneira crítica, dialógica, responsável e construtiva (BRASIL, 1998; RIO GRANDE DO SUL, 2009; SIMÕES et al, 2012; SCHLATTER; GARCEZ, 2012).

Dentre tantas possibilidades de linguagens a serem trabalhadas em sala de aula de Português como Língua Adicional (PLA) no âmbito do Programa de Português para Estrangeiros (PPE) da UFRGS, o curso Prática Cinematográfica, abordado neste trabalho, enfoca o gênero do discurso cinema, o primeiro gênero audiovisual da história, que revolucionou a sociedade do século XIX e, desde então, faz parte da vida de tantas pessoas "sejam elas estudiosas ou leigas, seja para divertir ou filosofar" (HILGERT, 2014, p. 35), para dormir ou despertar. Mas por que o cinema? Por que ensinar alunos estrangeiros a produzir cinema? De que forma esse gênero específico se relaciona com o ensino de PLA?

Neste artigo, apontamos alguns caminhos que temos percorrido para problematizar uma questão que consideramos de profunda importância: as possíveis potências em relacionar o ensino de PLA com a linguagem cinematográfica. Acreditamos que essa tem sido uma forma de aproximar ensino de língua, pensamento ético e sensibilização estética - aproximações essas que podem desestabilizar formas por vezes já sedimentadas de se pensar educação e ensino de PLA.

\section{Linguagem, tecnologias e multiletramentos}

Partimos da premissa de que é através da linguagem que os sujeitos se inserem no mundo e se constituem em práticas sociais (BAKHTIN, 2003; CLARK, 1999). Conforme proposto pelo filósofo russo Mikhail Bakhtin (2003), o uso da linguagem se dá nas diferentes esferas de atividade humana através de enunciados locais, situados e únicos, em responsividade a enunciados anteriores. Embora cada enunciado seja sempre individual e singular, "cada campo de utilização da língua elabora seus tipos relativamente estáveis de enunciados, os quais denominamos gêneros do discurso" (BAKHTIN, 2003, p. 262). Os gêneros do discurso são, portanto, construções sóciohistóricas e, ao mesmo tempo, são (re)construídos a cada interação na cadeia da comunicação discursiva. 
Nossos alunos e nós professores, hoje, vivemos através de gêneros orais, escritos e multimodais ${ }^{4}$ implicados ou criados pelas novas tecnologias. Um texto de jornal pode ser acessado em um site, uma notícia pode ser assistida em um vídeo de YouTube, uma mensagem pode ser transmitida através de áudio, vídeo, foto ou meme, por exemplo, e tudo isso pode ser consumido e praticado fácil e rapidamente através da internet, das redes sociais, da velocidade e diversidade de acesso à informação e comunicação. Em tempos de Netflix, Whatsapp, Youtube, Facebook, é evidente que as tecnologias revolucionaram as interações sociais e a comunicação, mas o que fazemos com elas? Como lidamos com essa velocidade de informação, com as novas formas de interagir na e pela linguagem?

Consideramos relevante a reflexão para um posicionamento acerca de tudo que se consome. As informações trazidas pela mídia, a possível manipulação de notícias e, por isso, a dificuldade de selecionarmos fontes de informações que sejam, talvez, menos tendenciosas assolam as discussões educacionais preocupadas com a formação de sujeitos críticos, capazes de selecionar e consumir textos de modo menos ingênuo e manipulável. Mas como o ensino pode trabalhar a favor da participação crítica na sociedade?

Conscientes do espaço que a tecnologia e os novos gêneros do discurso fomentados por ela ocupam no âmbito da comunicação, bem como as relações pósmodernas que se dão e, muitas vezes, dependem da tecnologia para existir, nos questionamos, portanto, como viver (n)essa velocidade que as relações operam, sem considerar suas implicações no uso da linguagem. Rojo (2009) defende que as práticas de letramento na escola devam "[...] dar conta as demandas da vida, da cidadania e do trabalho numa sociedade globalizada e de alta circulação de comunicação e informação, sem perda de ética plural e democrática [...]” (p. 90). Alinhadas à autora, entendemos que o ensino deva estar a serviço das demandas sociais, possibilitando a reflexão sobre o uso de tecnologias e os multiletramentos imbricados, de modo a formar cidadãos mais críticos quanto a isso.

Conforme Rojo (2009), o conceito de multiletramentos faz referência “[...] às novas práticas de letramento que envolvem a multiplicidade de linguagens e mídias presentes hoje na criação de textos (multimodalidade) e também a diversidade cultural

${ }^{4}$ Em 1920, começou a se abordar multimodalidade como uma perspectiva da pedagogia da percepção e, somente nos anos 1930, a Escola de Praga desenvolveu o primeiro estudo sobre multimodalidade, tendo como objeto de estudo a linguagem nas artes visuais e no teatro (VAN LEEUWEN, 2005, p. 688). 
relacionada aos produtores e leitores de tais textos" (p. 168-169). Assim, trabalhar com multiletramentos em sala de aula é também uma abordagem multicultural que possibilita novos usos, reflexões e práticas de aprendizagem relativas à sociedade multiletrada em que vivemos, explorando criticamente novos processos de leitura e escrita suscitados pelas tecnologias (TEIXEIRA; LITRON, 2012; BULLA; SILVA, 2017).

\section{Imagens e perigos de nosso tempo}

A proliferação de imagens em nosso cotidiano é quase banal e muitas vezes nem mesmo paramos para pensar no quanto somos mediados por elas. Há nisso fascínio e perigo. Perigo não necessariamente como algo ruim, mas no sentido que Michel Foucault (2010) denomina "perigos do nosso tempo", ou seja, algo para o qual devemos nos atentar, problematizar, produzir pensamento sobre. A psicanalista Maria Rita Kehl sintetiza:

Em todas as épocas o poder se faz representar em imagens; mas nossa época é a única capaz de produzir imagens em escala industrial, com possibilidade de difusão planetária. A única capaz de produzir imagens para todos os fenômenos da vida social, imagens simultâneas aos acontecimentos, traduções do real editadas e emitidas tão depressa que imagem e real, trauma e sentido se confundem na percepção do espectador. Em todas as épocas o poder se traduz em imagens, mas nossa época é a única em que o eixo central do poder, que já não é a política mas o capital, concentra-se sobretudo nos polos de produção e difusão de imagens. (KEHL, 2015, p. 88)

Em artigo intitulado "Imagens da violência e violência das imagens", Kehl (2015) afirma categoricamente que "toda imagem tem um potencial de violência" (p. 86). O potencial de violência, segundo a autora, é ainda mais potente quando se trata do cinema. E essa violência está muito ligada à ilusão de verdade que o cinema nos passa, que, segundo a autora, nos deixa apaziguados pelo "poder reconfortante da imagem" (p. 87). Seria, então, uma violência causada, paradoxalmente talvez, pelo seu potencial apaziguador. O que a autora parece defender é que há perigo na falta de pensamento sobre imagem, na aceitação passiva do cinema como um retrato da realidade tal como ela é, e que por isso não exigiria quase nenhum esforço para compreendê-lo. A violência não está na imagem em si, mas na relação que estabelecemos com ela. E em um mundo onde imagens são produzidas em massa, em escala industrial, podemos cair no risco de não as problematizar. 
A acreditamos que uma aula de cinema (tanto no curso de Cinema Brasileiro do PPE, que trabalha com alunos como espectadores, quanto no Prática Cinematográfica, no qual alunos são centralmente produtores) pode ser um lugar privilegiado de pensamento sobre imagem. Especialmente quando pretendemos trabalhar com filmes que questionem um certo status quo social e imagético. A partir do momento que reconhecemos a importância da produção de imagens em nosso cotidiano, podemos considerar também essa uma preocupação urgente da educação. Nos parece fazer sentido unir o ensino de PLA com essa problematização da violência das imagens proposta por Kehl (2015), de modo a ampliar a participação crítica dos nossos alunos estrangeiros em práticas de multiletramentos.

Em uma aula de Prática Cinematográfica tal qual a concebemos, os alunos têm acesso a um cinema que educa e faz pensar, que provoca e quebra clichês sobre imagem, cultura, sociedade e linguagens. Acreditamos ser de suma importância incluir em um curso de PLA, assim como em aulas de línguas na escola, a possibilidade de interagir com e produzir imagem, tirando o aluno de uma postura apaziguadora de consumidor das "imagens-indústria" e colocando-o mais próximo de um lugar de crítica e protagonismo nesse mundo tão mediado por imagens.

\section{Relações entre cinema e ensino de PLA}

Partimos dos estudos do pesquisador e professor de cinema brasileiro Ismail Xavier sobre o lugar do espectador de cinema como um espaço privilegiado de ampliação das possibilidades do olhar. Xavier (2003) teoriza sobre um possível "olhar sem corpo do cinema". Sem corpo porque as nossas limitações corpóreas são quebradas pelos travelings e zoom da câmera, pelos flashbacks e slow motion etc.; ou seja, tudo aquilo que faz parte da linguagem especificamente cinematográfica é visto pelo autor como um impulsionador na relação entre o espectador e o filme ao qual está assistindo. Xavier (2003) descreve com fascinação a posição privilegiada do espectador que parece poder saltar por todos os cantos junto às mais diferentes técnicas cinematográficas:

Puro olhar, insinuo-me invisível nos espaços a interceptar os olhares de dois interlocutores, escrutinar relações e gestos, explorar ambientes, de longe, de perto. Salto com velocidade infinita de um ponto a outro, de um tempo a outro. Ocupo posições do olhar sem comprometer o corpo, sem os limites do meu corpo. Na ficção cinematográfica, junto com a câmera, estou em toda parte e em nenhum lugar (p. 36). 
De modo complementar, Jaques Aumont, importante estudioso da área do cinema, chega ao ponto de afirmar que um filme não é nada sem o seu espectador "senão uma sucessão de sombras, de formas e de cores, literalmente 'não-identificáveis' em uma tela" (AUMONT, 1995, p. 259). Essa talvez seja uma opinião radical, mas que serve para entendermos que o espectador que está ali, na sua "presente-ausência”, não é passivo; essa ausência é marcada por uma presença que significa. O espectador é colocado ali para preencher vazios, ressignificar, ser protagonista e, ao mesmo tempo, aceitar as imposições postas pelo próprio filme. E, nesse jogo, algo sempre escapa ao espectador, que, da mesma forma que não é passivo, também não é soberano e portador da verdade (MARCELLO, 2008). E justamente em virtude da percepção desse lugar ativo, de ser também produtor daquilo que se assiste, que vemos no aluno o potencial de fazer cinema, de produzir o seu próprio filme. Um lugar não existe sem o outro, não se desvincula. Nunca deixamos de ser espectadores porque passamos a ser diretores, roteiristas etc. $\mathrm{O}$ produtor de cinema só existe porque começou já a fazer cinema na medida em que assistia a filmes que instigavam, desacomodavam, provocavam participação.

Trazemos essas constatações para ressaltar algo que nos parece de extrema importância para pensar sobre cinema e educação: a relação entre um filme e o espectador. Não o filme em si, não a interpretação que possa ser feita de um filme, mas a relação que nunca se esgota, que nunca é unilateral. É justamente essa relação tão cheia de possibilidades que consideramos cara a este estudo e ao contexto de sala de aula que analisamos aqui. A presença do cinema e, mais ainda, do estudo da sua linguagem para uma prática cinematográfica, parece-nos potente para o aprendizado de uma língua.

Colocando esse enfoque maior na relação que pode se estabelecer entre espectador e filme, acreditamos também retirar do cinema o caráter de instrumento, de ferramenta para o ensino de uma língua. O cinema não está na sala de aula a serviço da aprendizagem do Português, isso seria diminuir muito as potências de uma arte tão rica. Apostamos aqui que seja possível integrar o ensino de PLA com a prática cinematográfica, multiplicando assim as possibilidades de desenvolvimento de um pensamento crítico e criativo, ou seja, um ensino de língua que passa por uma experiência ético-estética.

Ao nos referirmos à experiência ético-estética, primeiramente vale destacar que tanto ética como estética não são aqui vistos como conceitos fixos, mas sempre 
moventes, sempre existentes em relações. A ética não é somente a conduta de uma pessoa, a moral de vida de alguém, mas está presente na relação dessa pessoa com outras ou com ela mesma. Da mesma forma, a estética não é algo encontrado em uma obra de arte, mas faz parte da relação entre um observador, a arte e aquilo que essa situação envolve.

Nadja Hermann (2002), a propósito, justifica o uso conjunto entre ética e estética. Ao resgatar histórica e filosoficamente os mais diversos conceitos já elaborados sobre ética e estética, a pesquisadora chega à conclusão de que "a experiência estética é uma via de acesso possível para a vida moral" (HERMANN, 2002, p. 12). Essa ligação entre ética e estética está também bastante atrelada aos estudos do filósofo Friedrich Nietzsche, sobre aparência e essência, em que o pensador traz a relação com arte e vida do mundo dionisíaco e apolíneo, explorando essas duas formas, para afirmar que não há divisão entre aparência e essência, não há nada por trás da superfície, não há verdades a descobrir. Nessa linha e recorrendo ao pensamento filosófico nietzschiano, Hermann (2002) afirma que "somente a arte trata a aparência como aparência e não como um mundo verdadeiro" (p. 14), e, a partir disso, podemos ressaltar uma certa potência da arte para enfrentar o mundo da forma como Nietzsche defendeu: sem buscar a verdade por trás da aparência. E, com tal potência, a arte pode proporcionar um pensamento ético, um olhar diante de nossa conduta ética.

É justamente na esteira desse pensamento que operamos com o conceito de experiência ético-estética na aula de Prática Cinematográfica no contexto do ensino de PLA. Acreditamos que a relação desses alunos com a cultura brasileira, com suas vivências em um país estrangeiro e com o aprendizado de uma outra língua é complexificado pela presença de um cinema que os provoca, que dá acesso a uma sensibilização ética e estética.

Outro importante ponto a ser destacado é que não falamos aqui de qualquer cinema. Esse que multiplica as possibilidades do olhar, segundo Xavier (2003), não pode ser qualquer filme. Em entrevista concedida à revista Educação \& Realidade, Xavier (2008) defende que um "cinema que educa é um cinema que (nos) faz pensar", asserção que justamente intitula a entrevista. Ele desenvolve essa ideia tratando especialmente do filme que quebra com dicotomias, que vai além dos clichês tão bem estabelecidos nessa arte que carrega em si o paradoxo de ser uma "arte de massas"5.

\footnotetext{
5 Alain Badiou (2004) trata dessa questão para nos mostrar o quanto o cinema exige um pensamento
} filosófico justamente por ser tão paradoxal. O cinema é arte e é de massa. Ele é popular ao mesmo tempo 
Xavier (2008) se refere especialmente ao cinema que não tenta ser um "retrato da realidade", ou um julgamento moral sobre alguma coisa. O cinema que nos faz pensar (e que por isso educa) seria aquele que incomoda, mais do que apazigua. Aquele que quebra com ideias prontas, mais do que aquele que apenas nos mostra algo que já sabemos. Cinema que educa, que nos faz pensar, que nos desacomoda é o cinema que passa por uma experiência de sensibilização estética e pensamento ético.

Embora nos alinhemos fortemente à proposição de Xavier (2008), acreditamos também que o cinema que não desacomoda, o cinema clichê (como vários filmes hollywoodianos preferidos por vários alunos), pode oportunizar um trabalho problematizador se inserido em projetos de aprendizagem (HERNÁNDEZ, 2008) e com tarefas orientadas para a promoção de multiletramentos. Um projeto de investigação sobre representações da mulher brasileira ou da identidade de brasileiro no cinema, por exemplo, com tarefas que convidem os alunos à análise, reflexão e crítica, tem o potencial de fomentar experiências ético-estética também sensibilizadoras e transgressoras.

\section{O curso de Prática Cinematográfica}

O curso Prática Cinematográfica foi criado em 2016 para compor o hall de mais de 30 disciplinas de PLA ofertadas pelo PPE/UFRGS, um programa de extensão que, desde 1993, tem por objetivos formar professores de PLA e oferecer aulas de português a alunos estrangeiros com ou sem vínculo com a universidade ${ }^{6}$. Os cursos são elaborados a partir de diferentes temáticas e gêneros do discurso (BAKHTIN, 2003) para proporcionar a aprendizagem de PLA pelo uso da linguagem em interação social (CLARK, 2000). Alguns cursos são organizados por temáticas, implementadas através de unidades didáticas, e incluem a realização de alguns projetos de aprendizagem (HERNÁNDEZ, 2008); já outros são configurados exclusivamente a partir de projetos (KRAEMER, 2012). Essas metodologias de aprendizagem, acreditamos, proporcionam

em que é só para "os especialistas". Essa característica tão peculiar é apresentada por Badiou (2004) como uma complexidade que deveria ser pensada a partir de múltiplos questionamentos filosóficos, questionamentos que não serão respondidos, mas serão provocadores e criarão a possibilidade de ainda mais produção de pensamento. Destacamos, então, mais um aspecto específico do cinema que o torna tão potente, especialmente em um contexto de educação que se pretende questionador e inventivo.

${ }^{6}$ O PPE foi fundado e coordenado até 2015-1 pela Profa. Dra. Margarete Schlatter; desde 2015-2, é coordenador pela Profa. Dra. Gabriela da Silva Bulla, professora que ingressou para a área específica de PLA na UFRGS em 2012 e atuou como coordenadora adjunta do programa de 2012-2 a 2015-1. Mais informações em: 〈www.ufrgs.br/ppe>. 
mecanismos para que os alunos se insiram na e pela linguagem nas diferentes esferas de atividade humana, se constituindo como sujeitos em português e escolhendo de modo crítico e autoral do que querem participar e como.

O curso Prática Cinematográfica trabalha de acordo com as orientações teóricas e pedagógicas do PPE. É um trabalho realizado inteiramente como um projeto de aprendizagem, que, como já afirmamos, visa ao ensino da linguagem audiovisual ${ }^{7}$ e de PLA e objetiva a produção de um curta metragem de autoria coletiva.

Nos relacionamos com esse curso do mesmo modo que os estudos em Linguística Aplicada e Educação - nossas áreas de interesse - têm procurado atuar: através da transdisciplinaridade. De acordo com Signorini e Cavalcanti (1998),

Transdisciplinaridade envolve mais do que a justaposição de ramos do saber. Envolve a coexistência em um estado de interação dinâmica. [...] A mera justaposição de saberes não leva à interação, condição essencial para a transdisciplinaridade. Não se buscam contribuições de outras áreas, mas sim, a participação ativa dos pesquisadores das áreas envolvidas, a fim de se dar conta da problematização que a abordagem do objeto de estudo proposto provoca em cada área. (p. 133)

Reconhecemos tanto as dificuldades, quanto as necessidades de se trabalhar dessa forma, tendo em vista que, em muitos momentos, é transdisciplinar o modo pelo qual a vida acontece. E a produção de cinema, em si, é um processo transdisciplinar.

A primeira edição do curso foi oferecida no segundo semestre de 2016, sendo ministrada por dois professores-bolsistas, um da Letras e outro do Cinema, de modo a potencializar a transdisciplinaridade a partir da colaboração entre olhares disciplinares. Hoje, o curso já teve quatro ofertas e, consequentemente, quatro distintas abordagens de currículo. As duas primeiras edições do curso totalizaram 45 horas ao longo um semestre, divididas em 15 encontros; já as duas últimas somaram 60 horas. Os alunos participantes são adultos de diferentes países, falantes de diferentes idiomas, e participantes de cursos dos níveis Português para Falantes de Espanhol, Intermediário I, Intermediário II e Avançado ${ }^{8}$.

Justificamos a possibilidade de ensino multinível nesse curso por sua caracterização mais ativa e inclusiva, dentro da perspectiva de projetos (HERNÁNDEZ, 2008). Muitos dos trabalhos são realizados em grupos ou em duplas o que acreditamos

\footnotetext{
${ }^{7}$ Entendemos a representação narrativa, imagem-em-movimento, representação e comunicação presente em um filme como texto.

${ }^{8}$ O PPE oferece aulas do nível Básico I ao nível Avançado (ver Kraemer, 2012).
} 
ser positivo para a aprendizagem de línguas adicionais orientada por um viés interacional. Alunos com mais proficiência em PLA podem ajudar alunos com menos proficiência na realização de atividades de produção e de compreensão; e todos podem aprender com as contribuições dos outros. Acreditamos que ajudar também é uma forma de aprender e que o compartilhamento de ideias para a realização de práticas em sala de aula pode oportunizar momentos de trocas e ajudas, e, principalmente, de uso da linguagem, de diálogo em português, além dos importantes debates culturais que a presença do cinema acaba muitas vezes promovendo.

O trabalho com gêneros orais, escritos e multimodais é realizado através de etapas como, por exemplo, contextualização do tema, (re)conhecimento do assunto, apropriação do gênero, perguntas de leitura, produções textuais. Conforme sintetizado por Silva (2017), o trabalho realizado no curso Prática Cinematográfica do PPE pode oportunizar:

$\checkmark$ o diálogo em português entre a equipe para definir o argumento do filme;

$\checkmark$ a escrita de um roteiro;

$\checkmark$ a apropriação de determinada linguagem para os atores que irão interpretar os personagens, além do aperfeiçoamento da pronúncia em português;

$\checkmark$ a sistematização de uma narrativa em formato storyboard;

$\checkmark$ o aprendizado e uso dos planos [cinematográficos] em português;

$\checkmark$ o envolvimento e trabalho em equipe;

$\checkmark$ a inversão de papeis de sujeito consumidor para sujeito produtor de cinema, imprimindo suas ideias, criações e vontades de expressar em um filme, em português. (p. 12)

Assim, nossos alunos, nas quatro edições do curso, já são produtores de filmes ficcionais em formato curta-metragem, documentários, filmes em stopmotion, bem como dos cartazes de seus próprios filmes, roteiros, sinopses, entre outros.

$\mathrm{O}$ ensino e a aprendizagem de técnicas audiovisuais imbricadas em uma proposta pedagógica que visa oportunizar novas perspectivas e possibilidades sobre um gênero do discurso tão presente em nosso cotidiano pode ser também uma alternativa para conhecer nossos alunos, seja através de seus olhares sobre filmes que assistem, seja através dos filmes que produzem. Além dos (belíssimos) produtos finais já realizados por nossos alunos, essa experiência transdisciplinar nos proporciona reflexões sobre ensino-aprendizagem de línguas adicionais através dos gêneros multimodais, e o cinema como possibilidade de sensibilização ética e estética, para além de um instrumento. 


\section{O cinema como incômodo ético-estético: Recife Frio}

Para exemplificar o que até o momento teorizamos, discutimos aqui um relato de uma das aulas de Prática Cinematográfica. No planejamento do semestre, a aula três foi dedicada a gêneros híbridos e funções de uma equipe de cinema - a partir da ideia que havia sido levantada pelos próprios alunos na aula anterior, de que documentário era realidade e ficção era invenção. Optamos, portanto, por apresentar filmes híbridos, sem assim classificá-los antes de sua exibição. Os filmes exibidos nessa aula contavam com legendas em português, o que ajudou na compreensão. Para essa aula, levamos dois filmes: Recife Frio e Ilha das Flores. No primeiro, uma narração é feita em quase todo filme, em outro idioma - espanhol, com legendas em Português, mas ainda assim pedimos que alunos de nível Avançado e Intermediário II ajudassem os colegas do Intermediário I, durante o filme, dispondo-os sentados em duplas.

Iniciamos a aula fazendo um brainstorm com a palavra Recife, antes de exibir Recife Frio. Um aluno contou que já havia ido a Recife. Os demais alunos já sabiam que Recife se situa no nordeste do Brasil, que é uma cidade muito turística, com praias bonitas. Após esse levantamento, realizamos uma atividade de leitura de uma reportagem que tratava das ilhas de calor em Recife ${ }^{9}$, com perguntas de leitura e reflexão linguística sobre o texto-base. Com isso, se explorou a leitura do gênero reportagem, o conhecimento prévio dos alunos sobre uma cidade turística brasileira, se discutiu sobre problemas ambientais que provocam calor em Recife. Logo após, exibimos o filme.

Os alunos pareceram muito espantados com o resultado que o documentário apresentava. Os alunos haviam entendido previamente que faz calor em Recife, que lá tem praias bonitas e que a cidade é conhecida por suas belezas naturais, que de tão bela conquista muitos turistas. Recife Frio (2009), de Kleber Mendonça Filho, mostra uma cidade devastada por um inverno surpreendente. Os alunos compraram a ideia do filme, já que entenderam que "documentário é realidade", sem mesmo perceber ou duvidar de alguns exageros do filme, como a migração de pinguins argentinos para a capital pernambucana. Após a exibição do filme, contamos aos alunos que isso nunca aconteceu em Recife, que o filme é uma ficção explorada em formato documental. A turma, inicialmente, se agitou com a notícia e as perguntas começaram a surgir. Os

\footnotetext{
${ }^{9}$ Adaptado de:

<http://jconline.ne10.uol.com.br/canal/cidades/cienciamambiente/noticia/2012/03/19/recife-e-suas-ilhasde-calor-36221.php>. Acesso em: 20 set. 2018.
} 
alunos pareceram deixar de gostar do filme naquele momento, mas, com as discussões que abrimos, entenderam que a questão principal do filme vai além do que é ou não verdadeiro. Eles conseguiram compreender a ironia que foi utilizada pelo autor da obra para falar de verdades em um filme ficcional, como a relação do quarto da empregada com a senzala, levantada na discussão por um dos estudantes.

Essa situação nos revelou alunos que se sentiram de certo modo traídos pela ficção, pela inventividade do cinema de gênero híbrido. Ficaram extremamente confusos, deixaram de gostar de um filme que durante toda a exibição os havia agradado. O debate gerado nessa aula, a quebra de expectativas e clichês foi muito produtivo, tanto para uma reelaboração sobre cinema quanto para o próprio aprendizado da língua. Os alunos ficaram tão incomodados que se engajaram em um debate com a turma e as professoras, fazendo com que eles produzissem conhecimento sobre cinema em português. Aqui língua portuguesa e linguagem cinematográfica se entrecruzaram num jogo repleto de incômodos potencialmente criativos.

De fato, Recife Frio é um filme provocador e foi incluído no programa do curso exatamente por isso. Esse nos parece um filme que tem potencial de proporcionar uma experiência ético-estética, de chamar o espectador para fazer parte da sua construção de modo provocador e crítico. Ao brincar com um gênero tão consagrado do cinema (o documentário), Kléber Mendonça inventa uma nova ficção, e, também, uma nova possibilidade de verdade $^{10}$ na arte cinematográfica. Os próprios alunos conectaram rapidamente documentário com verdade e vimos ali uma oportunidade de educação do olhar, de quebra daquilo que parecia tão claro, tão transparente para a turma. É através desse choque que o cinema pode complexificar as relações dos alunos com cultura, língua e linguagens. Uma experiência como essa deixa todas as nossas "crenças" em suspenso e abre espaço para desconstruções do que tínhamos dado como pronto, fechado, sedimentado.

\section{Cinema, PLA e alteridade}

${ }^{10} \mathrm{O}$ debate sobre as relações do cinema com conceitos de verdade e realidade é um dos mais importantes e vastos dentro do campo cinematográfico, porém sobre o qual não iremos discorrer aqui. Destacamos apenas o quanto uma simples quebra de expectativa em relação a um gênero de filme pode provocar uma grande perturbação em espectadores menos acostumados com um cinema mais questionador. Essa discussão parece que nunca se esgota, considerando que as barreiras entre ficção/cinema/realidade já foram quebradas e novamente reconstruídas tantas vezes, tornando esse um dos temas centrais para quem quer pensar sobre as relações entre um filme e seus espectadores. 
Considerando o contexto de sala de aula explorado aqui, não podemos ignorar um outro fator extremamente importante: o contato com o outro, ou seja, as relações de alteridade provocadas pela presença de um cinema estrangeiro (em uma turma de estrangeiros de diversos países). Cada filme ou curta escolhido para as aulas carrega uma complexa produção cultural brasileira que, por isso, pode provocar mais ainda os alunos de outras culturas. O próprio conceito de estrangeiro se transforma em uma aula de cinema, considerando que um filme causa distintos distanciamentos e aproximações em relação ao diferente, ou aquele que acabamos descobrindo não ser tão diferente assim. Essa presença radical e inegável de diferenças é uma situação que permite rupturas, rumores, relações de quebra, questionamentos, reformulações. Interessa aqui, então, pensar o cinema, a experiência estética com o cinema e a alteridade, a partir de um ponto de vista da ordem do olhar, da experiência demorada que nos atravessa, da potência da linguagem cinematográfica em desestabilizar, provocar pensamento e transcender a diferença cultural.

Acreditamos, portanto, que a aula de Prática Cinematográfica para estrangeiros exige a todo o momento um deslocamento de nossa zona de conforto (tanto por parte dos alunos quanto dos professores). Talvez seja mais apropriado ainda falar em deslocamentos de múltiplas zonas de conforto: em relação à(s) língua(s), às nossas concepções de arte e cinema e à alteridade radical em que somos colocados em contato. É justamente isso que se configura como uma possibilidade de experiência ético-estética que pode potencializar o ensino de PLA de uma forma transdisciplinar, múltipla e inventiva.

\section{Educação do olhar e escrita do roteiro}

Em uma aula de língua estrangeira, para que os alunos produzam textos de qualquer gênero, é necessário que tenham acesso a recursos linguístico-discursivos que possibilitem a participação em um diálogo com um colega, em uma discussão oral (como em um debate) ou escrita (como em um artigo de opinião ou em comentários em sites) etc. E ao selecionarem tais recursos para realizarem ações em diferentes interações em aula é que a aprendizagem da língua acontece gradualmente, em sequências de uso, reflexão e novamente uso da língua em contextos discursivos (BRASIL, 1998). 
Aplicamos essa mesma lógica em nossa aula de Prática Cinematográfica: se queremos que os alunos produzam curtas-metragens, precisamos ensiná-los como fazer isso, o que realizamos através do acesso aos e da reflexão sobre os recursos necessários para a produção desse gênero específico. Nesse sentido, não estamos nos referindo somente aos conhecimentos técnicos, mas também à elaboração criativa e potente do cinema. Os alunos precisam de referências (como Recife Frio) que fomentem o pensamento crítico, que desestabilizem, que quebrem com o que já é conhecido e abram espaço para o inusitado.

Como falamos anteriormente, a produção de cinema começa já no ato de assistir a um filme. Por isso uma das nossas preocupações, como já apresentamos aqui, é qual cinema traremos para as aulas. Os filmes aos quais iremos assistir com os alunos formarão seus repertórios juntamente com suas referências prévias de cinema. Se queremos que eles produzam curtas criativos, precisamos construir um espaço de reflexão cinematográfica nas aulas. Assim como precisam estar presentes em aula os tantos gêneros do discurso que o cinema envolve (como roteiro, sinopse, storyboard etc.) e com eles os recursos linguístico-discursivos necessários para suas produções.

Um exemplo de atividade pedagógica extremamente produtiva e que parece integrar de forma muito criativa e engajadora cinema e ensino de PLA é a escrita do roteiro. No Prática Cinematográfica, os alunos produzem o roteiro em grupos, sendo esse um gênero do discurso que nos parece adequado para a prática de escrita coletiva em um projeto de produção coletiva de um curta. Um roteiro de cinema tem muitas características técnicas específicas, além de ser um grande desafio escrever do ponto de vista de um olhar da câmera, ou seja, tentando descrever tudo que aparecerá na tela sem julgamentos ou detalhes que não podem ser filmados (como cheiros, pensamentos etc.). Além disso, é um gênero que exige dos alunos grande reflexão acerca da língua falada. É justamente aí que entra a importância da interação e escrita em grupo: é muito enriquecedor unir diferenças de níveis de conhecimento de português, de experiências interacionais com brasileiros, de relação com brasilidades. Esse é um momento de aprendizado em grupo em que vários tipos muito diferentes de conhecimentos e habilidades são valorizados.

Cada palavra do roteiro precisa ser pensada e debatida no grupo com muito cuidado. Os alunos-roteiristas precisam estar atentos às regras técnicas da escrita desse gênero do discurso, à criatividade e inventividade cinematográfica da narrativa, e aos diferentes usos do português que cada situação criada por eles exige, buscando alcançar 
efeitos de sentido desejados pelos autores. Tudo que será escrito precisa ser possível de filmar. Cada frase será dita por um ator que precisa entender plenamente o significado e a pronúncia necessária.

No semestre de 2018/1, tivemos uma situação em que os alunos estavam escrevendo um roteiro com duas cenas seguidas que exigiam o uso de linguagens e gêneros do discurso muito diferentes: uma conversa entre amigos e uma entrevista de emprego. Eles tiveram que compor as cenas com uma variedade de conhecimentos de língua, de etiqueta, de cultura e de cinema. $\mathrm{Na}$ interação entre os alunos, ficou evidente o entrecruzamento desses conhecimentos. Nesse sentido, destacamos o potencial também passível de vivência na produção de outros gêneros do discurso, como os literários - para o trabalho com outros gêneros por um viés ficcional inerente à produção dos curtas. O que é uma entrevista? Como podemos fazer uma entrevista verossímil no nosso filme? Que elementos multimodais e linguístico-discursivos lançaremos mão para a produção de efeitos de sentido, relações identitárias entre personagens e construção da entrevista dentro da nossa narrativa? São questões que atravessam a produção dos curtas e que possibilitam aprendizagens ético-estéticas, linguístico-discursivas, culturais e afetivas.

\section{Considerações finais}

O curso Prática Cinematográfica do PPE tem como objetivo explorar e produzir cinema atrelado à aprendizagem de PLA. No entanto, consideramos o cinema não como uma mera ferramenta para o ensino de português, mas como uma arte que tem o potencial de proporcionar uma experiência ético-estética de sensibilização diante do mundo e dos mais diversos modos que nos relacionamos com as linguagens. Para além da formação de cineastas, acreditamos que essa experiência educacional pode contribuir para a formação de cidadãos mais críticos enquanto interagentes com textos multimodais, sendo, portanto, mais uma possibilidade para o trabalho com multiletramentos na aula de PLA.

A discussão realizada neste artigo pretendeu mostrar o quanto trabalhar com cinema em um contexto de PLA pode ser uma combinação múltipla de gêneros do discurso e, ainda, de produção de pensamento filosófico. Entrecruzamos teorias de diferentes áreas do conhecimento justamente porque o cinema parece promover isso: um entrelaçamento entre aprendizados muito diferentes, mas que juntos podem 
reconfigurar e complexificar uma aula de PLA. Para tal empreitada, no entanto, é fundamental que o professor realize um percurso investigativo transdisciplinar acerca do objeto artístico-cultural que deseja incluir em sua aula, de modo a propor atividades pedagógicas capazes de explorar criticamente a complexidade do objeto e problematizar paradigmas.

A presença em si do cinema não é uma novidade nas salas de aula, no entanto, esse cinema parece ainda, na maioria das vezes, ser usado como instrumento, como algo para se alcançar um conhecimento extra fílmico. Procuramos mostrar aqui que o filme não precisa ser somente uma ponte para se aprender algo, mas o próprio aprendizado em si. Ao produzirem em conjunto um curta-metragem, os alunos se colocam em um lugar de protagonismo de uma produção audiovisual, que costuma inundar o nosso cotidiano. Assim, ao ocupar um espaço de crítico, consumidor, analista e produtor de conhecimento em um gênero do discurso tão presente em nossas vidas, os alunos têm o potencial de ampliar, de modo informado e questionador, suas relações com textos multimodais, suas experiências ético-estéticas, artísticas e culturais e sua participação como cidadão.

No livro "O prazer dos olhos: textos sobre cinema", do cineasta francês François Truffaut (2005), um capítulo em especial nos chama a atenção: "Porque sou o homem mais feliz do mundo" (TRUFFAUT, 2005, p. 327). O autor inicia com uma narrativa de uma situação que ele viu na rua, algo simples e rotineiro que chamou a sua atenção. Dessa narrativa, ele passa para outra: quase a mesma cena, mas agora com um final diferente. A segunda história não é mais um relato do que ele viu na rua, mas de uma cena filmada por ele. $\mathrm{O}$ que fascina Truffaut não é simplesmente o que ele observou no cotidiano, mas a possibilidade de recriar, modificar, transformar aquilo que ele vê através do cinema. O capítulo inteiro é feito de relatos como esse e de opiniões gerais sobre como deve ser o cinema. Ao final do texto, entendemos o título: Truffaut é o homem mais feliz do mundo porque faz cinema. Não seria esse um lindo convite para fazermos aos nossos alunos?

\section{REFERÊNCIAS}

AUMONT, J. A estética do filme. Campinas, SP: Ed. Papirus, 1995.

BAKHTIN, M. Estética da criação verbal. São Paulo: Martins Fontes, 2003.

BAKHTIN, M. Os gêneros do discurso. São Paulo: Editora 34, 2016. 
BADIOU, A. El cine como experimentación filosófica. In: YOEL, G. (Org.). Pensar el cine 1: imagen, ética y filosofia. Buenos Aires: Manantial, 2004. p. 23-81.

BRASIL. Parâmetros Curriculares Nacionais - terceiro e quarto ciclos do ensino fundamental: língua portuguesa. Brasília: MEC/SEF, 1998. Disponível em: <http://portal.mec.gov.br/seb/arquivos/pdf/portugues.pdf>. Acesso em: 06 ago. 2018.

BULLA, G. S.; SILVA, M. B. Escola, multiletramentos e tecnologias na aula de Língua Portuguesa: reflexões a partir de um projeto sobre Youtubers. Revista IberoAmericana de Estudos em Educação, Araraquara, v. 12, n. 4, p. 1984-1997, out./dez., 2017.

CLARK, H. H. O uso da linguagem. Cadernos de Tradução, Porto Alegre, n. 9, p. 4971, jan./mar., 2000.

FOUCAULT, M. Sobre a genealogia da ética: uma revisão do trabalho em curso. In: DREYFUS, H.; RABINOW, P. Michel Foucault, uma trajetória filosófica: para além do estruturalismo e da hermenêutica. Rio de Janeiro: Forense, 2010. p. 296-327.

HERNÁNDEZ, F. Transgressão e mudança na educação: os projetos de trabalho. Porto Alegre: Artmed, 1998.

HILGERT, A. V. Alteridade e experiência estética: o olhar, o outro e o cinema. Dissertação (Mestrado em Educação) - Faculdade de Educação, UFRGS, Porto Alegre, 2014.

HERMANN, N. Estetização do mundo da vida e sensibilização moral. Educação \& Realidade, v. 30, n. 2, p. 35-47, jul./dez., 2005.

KEHL, M. R. Imagens da violência, violência das imagens. Concinnitas, ano 16, v. 1, n. 26, jul., 2015.

KRAEMER, F. F. Português língua adicional: progressão curricular com base em gêneros do discurso. Dissertação (Mestrado em Letras) - Instituto de Letras, UFRGS, Porto Alegre, 2012.

MARCELlO, F. A. Criança e imagem no olhar sem corpo do cinema. Tese (Doutorado em Educação) - Faculdade de Educação, UFRGS, Porto Alegre, 2008.

MORÁN, J. Mudando a educação com metodologias ativas. Coleção Mídias Contemporâneas. Convergências Midiáticas, Educação e Cidadania: aproximações jovens. Ponta Grossa: Foca Foto-PROEX/UEPG, 2015. v. 2.

ROJO, R. Letramentos múltiplos, escola e inclusão social. São Paulo: Parábola Editorial, 2009.

RIO GRANDE DO SUL. Referenciais curriculares do estado do Rio Grande do Sul: linguagens, códigos e suas tecnologias. Porto Alegre: Secretaria do Estado da Educação/ Departamento Pedagógico, 2009. 
SILVA, M. B. Luz, câmera, ação! Prática Cinematográfica em aula de Português como Língua Adicional. Trabalho de conclusão de curso (Licenciatura em Letras) - Instituto de Letras, UFRGS, Porto Alegre, 2017.

SIMÕES, L. J.; RAMOS, J. W.; MARCHI, D.; FILIPOUSKI, A. M. Leitura e autoria: planejamento em Língua Portuguesa e Literatura. Erechim, RS: Edelbra, 2012.

SCHLATTER, M.; GARCEZ, P. Línguas Adicionais na escola: aprendizagens colaborativas em inglês. Erechim, RS: Edelbra, 2012.

TEIXEIRA, A.; LITRON, F. F. O manguebeat nas aulas de Português - Videoclipe e movimento cultural em rede. In: ROJO, R.; MOURA, E. (Orgs.). Multiletramentos na escola. São Paulo: Parábola Editorial, 2012. p. 167-180.

TRUFFAUT, F. O prazer dos olhos: textos sobre cinema. Rio de Janeiro: Jorge Zahar Ed., 2005.

VAN LEEUWEN, T. Multimodality. In: SIMPSON, J. (Ed.). The Routledge Handbook of Applied Linguistics. Londres: Routledge, 2011. p. 668-682.

XAVIER, I. O Olhar e a Cena - Melodrama, Hollywood, Cinema Novo, Nelson Rodrigues. São Paulo: Cosac \& Naify, 2003.

XAVIER, I. Um cinema que "educa" é um cinema que (nos) faz pensar: entrevista com Ismail Xavier. Educação \& Realidade, Porto Alegre, v. 33, n. 1, p. 13-20, jan./jun., 2008.

\section{Como citar este artigo:}

BULLA, Gabriela da Silva.; HILGERT, Ananda Vargas.; BULEGON,. Prática cinematográfica: o cinema como potencial ético-estético e transdisciplinar na aula de português como língua adicional. Revista Ibero-Americana de Estudos em Educação, Araraquara, v. 13, n. 4, p. 1832-1850, out./dez., 2018. E-ISSN: 1982-5587. DOI: 10.21723/riaee.unesp.v13.n4.out/dez.2018.11806

Submissão em: 20/08/2018

Revisões requeridas: 03/09/2018

Aprovação final em: 29/09/2018 